\title{
A CASE OF VON HIPPEL'S DISEASE
}

BY

\section{E. V. SRINIVASAN}

S. A., male, aged 26 years, an educated young Government officer, consulted me on March 21, 1933, for slight diminution of vision of a week's duration in the right eye.

On examination, I found that he saw best with the glasses he was wearing, viz., R.E. $6 / 18 \bar{c}-2.0$ D. cyl., axis $105^{\circ}$ and

L.E. $6 / 6 \bar{c}-3.0$ D. cyl., axis $75^{\circ}$.

Finding the inside of the right upper lid somewhat congested, I examined the cornea with the slit-lamp microscope to eliminate the possibility of superficial punctate keratitis being the cause of the reduction of vision and found it free.

Ophthalmoscopically, the media were slightly muddy but with the Gullstrand's ophthalmoscope a very clear view of the fundus was obtained. The disc presented a normal appearance. The vessel emanating from it at " 2 o'clock" had two aneurysmal dilatations one very near the disc and the second well out in the periphery of the retina. The second saccular dilatation was in the midst of a tangle of vessels. The complexity of the appearance suggested a burst sac. From the middle of the vessel between the two knobs, a branch travelled down to the macula which presented a granular red circle of $\frac{1}{2}$ disc diameter.

The patient received a blow from a tennis ball seven years ago and the macular condition must, I think have been a sequel of Berlin's oedema or disease, quite independent of the angiomatous condition described in the beginning,

Otherwise the fundus was normal, except that there was a great tendency for corkscrew-like tortuosities of the finer and mediumsized vessels.

The left eye was absolutely normal, not even a single tortuous vessel being noticed.

History of the Case.-Parents are living, father 70 and mother 52 years of age, both enjoying good sight. There are two brothers and three sisters with no abnormality about the eyes. Patient was married a little over a year ago. Wife had no abortions and has not conceived yet.

Patient has occasional attacks of headache, severe at times, and suffers from chronic constipation. Urine normal. B.P. 116. Wassermann reaction negative when blood was examined a year ago by his physician for enlargement of liver and urticarial trouble.

As a student, he was studying hard, mostly at nights. He has been a cyclist for a number of years.

The nervous system was normal, with no suggestion of cerebral or cerebellar involvement. 
The duration of the condition must be said to be not less than three years, for he says that when he was refracted in the hospital and prescribed glasses; the doctors found the right eye not quite up to the mark, even at that time.

\section{ANNOTATION}

\section{Instruction for Medical Students in the Treatment of Ophthalmia Neonatorum}

In July, 1932, there was an annotation in our pages on the subject of instruction for medical students in the treatment of ophthalmia neonatorum. The attention of the General Medical Council had been drawn to this subject by a resolution passed at the Annual Meeting of the British Medical Association in 1931.

Ever since St. Margaret's Hospital was opened in September, 1918, it has been obvious that special facilities for instructing students and midwives in the treatment of this dread ophthalmic disease were available. The midwife students were not slow to avail themselves of the opportunity; but it is only during the past year that any considerable body of medical students has availed itself of the privilege, as is shown in the Report on page 238.

The Council of British Ophthalmologists has for some years past urged that some compulsory instruction in the treatment of ophthalmia neonatorum should form part of the medical students' curriculum. We understand that the result is largely due to the interest taken by the L.C.C. in the memoranda which have been placed hefore it by the Council of British Ophthalmologists and by Mr. Mayou. All concerned are much to be congratulated on the successful result of the past five years' work.

\section{ABSTRACTS}

\section{I.-GENERAL MEDICINE}

Garland, Hugh G. and Thompson, J. G. (Leeds).-Uveoparotid tuberculosis. (Febris Uveo-Parotidea of Heerfordt). Quart. Jl. Med., (New Series), Vol. II, No. 6, pp. 157-177, April, 1933.

This joint contribution by Garland and Thompson, physician and pathologist respectively, to the literature of uveo-parotid fever, 